\title{
COVID-19 and respiratory tract viral co-infections: Choosing the screening method
}

\author{
Amin Mohsenzadeh', Hoda Sabati2,** \\ ${ }^{1}$ Faculty of Science, Islamic Azad University of Ardabil, Iran \\ ${ }^{2}$ Biotechnology and Biological Science Research Center, Faculty of Science, Shahid Chamran University of Ahvaz, Iran
}

Keywords: COVID-19, SARS-CoV-2, Diagnostic, Co-infection, Secondary infection

The new pandemic pathogen, severe acute respiratory syndrome coronavirus 2 (SARS-CoV-2) or Coronavirus disease 2019 (COVID-19), causes a wide range of symptoms that differ from mild cold-like symptoms to pneumonia and death. This virus has been an international public health emergency since December, 2019 due to its high infectious rate. Beyond the pathogenesis of COVID-19, viral co-infections play a vital role in the occurrence and development of this pandemic by increasing the difficulties of diagnosis, treatment and even the disease symptoms and mortality. Regarding clinical presentation, transmission and coincidence this disease is very similar to Middle East respiratory syndrome (MERS), severe acute respiratory syndrome (SARS) and seasonal influenza which makes it difficult to accurately detect [1-3].

The COVID-19 detection and diagnostic methods are mainly divided into two groups, a laboratory-based (such as serological tests, and real-time reversetranscriptase polymerase chain reaction (RT-PCR)) and lung computed tomography (CT) scan or chest radiography. Accuracy of these methods related to their sensitivity and specificity. Previous studies showed that only some of them had both sensitivity and specificity over $50 \%$ in detecting SARS-CoV-2 infection. Therefore, the use of appropriate diagnostic

\footnotetext{
* Corresponding author:

Hoda Sabati, MSc

Biotechnology and Biological Science Research Center,

Faculty of Science, Shahid Chamran University of Ahvaz, Iran

Tel/Fax:+98 9226092051

Email: h.sabati@yahoo.com

https://orcid.org/oooo-0002-4473-7245
}

Received: January, 03, 2021

Accepted: January, 05, 2021 methods with sufficient accuracy is of particular importance in screening COVID-19 [4-6].

Several reports indicate that viral interactions have some effect on the course of infectious diseases. Therefore, high co-infection rate might be due to the overlap between the emergence of COVID-19 and other respiratory viruses. This overlap emphasizes the importance of the COVID-19 screening methods, regardless of other positive results for other viruses in the initial trials [7].

Although co-infection with dual respiratory viruses is uncommon in adults, but there were cases have been reported. Previous study showed that influenza A virus was one of the common viral pathogens causing co-infection among patients with COVID-19 which may have caused initial falsenegative results of RT-PCR for SARS-CoV-2 [8]. In a case report, co-infection of metapneumovirus and SARS-CoV-2 has been investigated [9]. Huang et al. reported a unique case of influenza $B$ virus co-infection with SARS-CoV-2 in Taiwan [10]. Other viruses that can cause co-infection include: coronavirus, rhinovirus/enterovirus, respiratory syncytial virus (RSV), parainfluenza [11-13]. Therefore, it is necessary to limit the risk of secondary infections by other viruses that can cause false-negative results for SARS-CoV-2 on screening methods and increase the risk of 
mortality rate in COVID-19 patients. Recognition of possible viruses causing co-infection among COVID19 patients helps clinicians to choose appropriate screening method, proper management and therapeutic $[7,14]$.

\section{Author Contributions}

All authors contributed equally to this manuscript, and approved the final version of manuscripts.

\section{Conflict of Interests}

The authors declare that they have no conflicts of interest.

\section{Ethical declarations \\ Not applicable.}

\section{Financial Support}

None to be declared.

\section{References}

1. Sharma A, Tiwari S, Deb MK, Marty JL. Severe acute respiratory syndrome coronavirus-2 (SARS-CoV-2): a global pandemic and treatment strategies. Int J Antimicrob Agents. 2020; 56(2):106054.

2. Gerges Harb J, Noureldine HA, Chedid G, Eldine MN, Abdallah DA, Chedid NF, et al. SARS, MERS and COVID-19: clinical manifestations and organ-system complications: a mini review. Pathog Dis. 2020; 78(4).

3. Chen X, Liao B, Cheng L, Peng X, Xu X, Li Y, et al. The microbial coinfection in COVID-19. Appl Microbiol Biotechnol. 2020; 104(18):7777-85.

4. Harahwa TA, Lai Yau TH, Lim-Cooke MS, Al-Haddi S, Zeinah M, Harky A. The optimal diagnostic methods for COVID-19. Diagnosis (Berl). 2020; 7(4):349-56.

5. Floriano I, Silvinato A, Bernardo WM, Reis JC, Soledade G. Accuracy of the Polymerase Chain Reaction (PCR) test in the diagnosis of acute respiratory syndrome due to coronavirus: a systematic review and meta-analysis. Rev Assoc Med Bras. 2020; 66(7):880-8.

6. Lisboa Bastos M, Tavaziva G, Abidi SK, Campbell JR, Haraoui L-P, Johnston JC, et al. Diagnostic accuracy of serological tests for covid-19: systematic review and meta-analysis. BMJ. 2020; 370:m2516.

7. Khodamoradi Z, Moghadami M, Lotfi M. Co-infection of Coronavirus Disease 2019 and Influenza A: A Report from Iran. Arch Iran Med. 2020; 23(4):239-43.

8. Lai CC, Wang CY, Hsueh PR. Co-infections among patients with COVID-19: The need for combination therapy with non-antiSARS-CoV-2 agents? J Microbiol Immunol Infect. 2020; 53(4):505-12.

9. Touzard-Romo F, Tapé C, Lonks JR. Co-infection with SARSCoV-2 and Human Metapneumovirus. R I Med J (2013). 202O; 103(2):75-6.
10. Huang BR, Lin YL, Wan CK, Wu JT, Hsu CY, Chiu MH, et al. Co-infection of influenza B virus and SARS-CoV-2: A case report from Taiwan. J Microbiol Immunol Infect. 2020. [In press]. doi: 10.1016/j.jmii.2020.06.011.

11. Su IC, Lee KL, Liu HY, Chuang HC, Chen LY, Lee YJ. Severe community-acquired pneumonia due to Pseudomonas aeruginosa coinfection in an influenza $\mathrm{A}(\mathrm{H} 1 \mathrm{N1})$ pdmog patient. J Microbiol Immunol Infect. 2019; 52(2):365-6.

12. Hung HM, Yang SL, Chen CJ, Chiu CH, Kuo CY, Huang KA, et al. Molecular epidemiology and clinical features of rhinovirus infections among hospitalized patients in a medical center in Taiwan. J Microbiol Immunol Infect. 2019; 52(2):233-41.

13. Huang SH, Su MC, Tien N, Huang CJ, Lan YC, Lin CS, et al. Epidemiology of human coronavirus NL63 infection among hospitalized patients with pneumonia in Taiwan. J Microbiol Immunol Infect. 2017; 50(6):763-70.

14. Si Y, Zhao Z, Chen R, Zhong H, Liu T, Wang M, et al. Epidemiological surveillance of common respiratory viruses in patients with suspected COVID-19 in Southwest China. BMC Infect Dis. 2020; 20(1):688. 